\title{
Effect of oscillation amplitude on the residence time distribution for the mesoscale oscillatory baffled reactor
}

\author{
H. W. Yussof ${ }^{1}$, S. S. Bahri, A. N. Phan' ${ }^{2}$, A. P. Harvey ${ }^{2}$
}

${ }^{I}$ Faculty of Chemical Engineering \& Natural Resources, Universiti Malaysia Pahang, Malaysia. ${ }^{2}$ School of Chemical Engineering \& Advanced Materials, Merz Court, Newcastle University, NE1 7 RU, UK. Article Info: Submitted on March 20, 2017, Accepted on June 20, 2017.

\begin{abstract}
A recent development in oscillatory baffled reactor technology is down-scaling the reactor, so that it can be used for the applications such as small-scale continuous production of bioethanol. A mesoscale oscillatory baffled reactor (MOBR) with central baffle system was developed and fabricated at mesoscales (typically $5 \mathrm{~mm}$ diameter). This present work aims to analyse the mixing conditions inside the MOBR by evaluating the residence time distribution (RTD) against the dynamic parameters of net flow Reynolds number $\left(R e_{n}\right)$ at $4.2,8.4$ and 12.6 corresponding to flow rates of 1.0, 2.0 and $3.0 \mathrm{ml} / \mathrm{min}$ respectively, oscillatory Reynolds number $\left(R e_{o}\right)$ between 62 to 622, and Strouhal number (Str) between 0.1 to 1.59 . The effect of oscillation frequency and amplitude on RTD performance were studied at frequency, amplitude, and velocity ratio ranging from 4 to $8 \mathrm{~Hz}, 1$ to $4 \mathrm{~mm}$ and 1 to 118, respectively. Effect of oscillation frequency has resulted in the variance of the RTD increased as the oscillation frequency increased from $5 \mathrm{~Hz}$ to $8 \mathrm{~Hz}$ and peak at $6 \mathrm{~Hz}$ of 0.264 . A further increase in the frequency above $5 \mathrm{~Hz}$ caused the RTD to slightly broaden and positively skewed. At frequency of $5 \mathrm{~Hz}$, the RTD profiles were close to Gaussian form for all tested amplitude values from $1 \mathrm{~mm}$ to $4 \mathrm{~mm}$. At low amplitudes, i.e. $\mathrm{x}_{\mathrm{o}}=1 \mathrm{~mm}$, the variance exhibited its minimum around 0.842 at $R e_{o}=156$. An increase in $R e_{o}$ above 300 resulted in increased in the variance rapidly to 1.28 , and later eliminated the plug flow behaviour and the reactor behaved similar to a single continuous stirred tank reactor.
\end{abstract}

Keywords: Mesoscale oscillatory baffled reactor; Residence time distribution.

\section{Introduction}

The mesoscale oscillatory baffled reactor (MOBR) which is currently being developed earlier for laboratory-scale processes, ${ }^{1}$ have received considerable attention due to their small volume and ability to operate at low flow rates, reducing reagent requirements and waste. ${ }^{2}$ They are suitable for continuous high throughput screening and pharmaceutical engineering, as plug flow behaviour can be easily achieved. ${ }^{3}$ MOBRs are millilitre scale OBRs designed for small scale screening of reactions. These mesoreactors combine the basic capabilities of the conventional OBRs such as enhanced heat and mass transport and product uniformity with small scale necessary for screening and production of specialist chemicals. Significantly, mixing inside oscillating baffled flows reactor can be controlled to a very high degree of precision, giving a wide range of mixing conditions, from soft mixing, exhibiting plug flow characteristics, to the most intense, approaching mixed flow conditions. ${ }^{3}$ In order to obtain the effecti intensification of the synthesis process for instances

Corresponding Author: Hafizuddin W. Yussof

Email: hafizuddin@ump.edu.my, Fax: +60-09-5492894 bioethanol, one needs to understand the fluid mechanics inside the reactor. The fluid mechanics inside continuous OBRs are governed by geometric parameters (baffle spacing and opened cross-sectional area) and dynamic parameters (Strouhal number, oscillatory Reynold number and net flow Reynold number). ${ }^{4}$ Geometric and dynamic parameters play an important role in the reactor design and operation. Scale-up can be performed by maintaining geometric and dynamic similarity. Geometric similarity is achieved by maintaining the baffle-spacing-todiameter ratio and the fractional open area of the baffle while dynamic similarity is achieved by maintaining the net and oscillatory flow Reynolds numbers. ${ }^{5}$ The oscillatory Reynolds number $\left(R e_{o}\right)$ measures the intensity of mixing inside a column or baffled reactor. ${ }^{2}$ It is similar to the net flow Reynolds number, $R e_{n}$, in steady flow, except that the superficial velocity $(u)$ has been replaced by maximum oscillatory velocity $\left(2 \pi f x_{o}\right)$. The Strouhal number is a measure of the effective eddy propagation. If it is too high, the eddies 


\section{Chemical Engineering Research Bulletin 19(2017) 111-117}

will be propagated into the next baffle cavity, thereby reducing the number of potential tanks-in-series. A velocity ratio is introduced in order to describe the interaction between oscillatory and net flows. It is the ratio of oscillatory $R e_{o}$ to net flow $R e_{n}$, and simplifies to the ratio of maximum oscillatory velocity to superficial velocity. In addition, the ratio of the two Reynolds numbers is a measure of the degree of plug flow. ${ }^{6}$

\section{Materials and Methods}

The summary of the geometric and dynamic parameters are expressed as in Eq. (1) - Eq. (6) as below.

Net flow Reynold number:

$$
R e_{n}=\frac{\rho d u}{\mu}
$$

Oscillatory Reynold number:

$$
\operatorname{Re}_{o}=\frac{2 \pi f x_{o} \rho d}{\mu}
$$

Strouhal number:

$$
S t r=\frac{d}{4 \pi x_{o}}
$$

Velocity ratio:

$$
\psi=\frac{\operatorname{Re}_{o}}{\operatorname{Re}_{n}}=\frac{2 \pi f x_{o}}{u}
$$

Baffle spacing:

$$
L=1.5 d
$$

Open cross sectional area:

$$
S=\left(\frac{d_{o}}{d}\right)^{2}
$$

where $f$ is the frequency of oscillation $(\mathrm{Hz}) ; x_{o}$ is the centre-to-peak amplitude of oscillation (m); $u$ is the superficial velocity of the liquid $(\mathrm{m} / \mathrm{s}) ; \rho$ is density $\left(\mathrm{kg} . \mathrm{m}^{-3} \cdot \mathrm{s}^{-1}\right) ; \mu$ is viscosity (Pa.s); $d$ is tube diameter (m); $d_{o}$ is orifice diameter (m) and $L$ is baffle spacing (m). The parameters applied to characterize plug flow condition for the mesoscale oscillatory helical baffled reactor are as follow: $1.27-10$ for $\operatorname{Re}_{n}, 0.30-2.0$ $\mathrm{ml} / \mathrm{min}$ for volumetric flowrate, $1-4 \mathrm{~mm}$ for oscillation amplitude and $0.5-14 \mathrm{~Hz}$ for frequencies. ${ }^{7}$

\begin{tabular}{|c|c|c|}
\hline Parameter & Symbol & Description \\
\hline $\begin{array}{l}\text { Centre to peak } \\
\text { amplitude of } \\
\text { oscillation }(\mathrm{m})\end{array}$ & $x_{o}$ & $\begin{array}{l}\text { Half the fluid } \\
\text { oscillation distance }\end{array}$ \\
\hline $\begin{array}{l}\text { Frequency of } \\
\text { oscillation }(\mathrm{Hz})\end{array}$ & $f$ & $\begin{array}{l}\text { Number of oscillation } \\
\text { per second }\end{array}$ \\
\hline $\begin{array}{l}\text { Volumetric flow } \\
\text { rate (e.g } \mathrm{ml} / \mathrm{min})\end{array}$ & $Q$ & $\begin{array}{l}\text { Volume of material } \\
\text { entering the OBR over } \\
\text { a given time period }\end{array}$ \\
\hline
\end{tabular}
The dimensionless groups and dynamic parameters required for oscillatory baffled reactor operation is presented as in Table 1.

Table 1: Overview design parameters of mesoscale oscillatory baffled reactor. ${ }^{8}$

The oscillation frequency $(f)$ and amplitude $\left(x_{o}\right)$ are the most important operational parameters in OFR. At a given $L$ and $d_{o}$, changing the combination of $f$ and $x_{o}$ allows control the generation of eddies and produces a range of fluid mechanical conditions as broad as required. The degree of dispersion increased linearly with the oscillatory velocity until a complete dispersion is achieved. ${ }^{10}$ In a yeast cell suspension study, ${ }^{11}$ the oscillatory $f$ and $x_{o}$ were found to affect the mass transfer measurements for wall baffles. It is proven when the oxygen mass transfer coefficient, $k L_{a}$ increased with the increasing of $f$ from 3 to $12 \mathrm{~Hz}$ for all the tested value of $x_{o}$ from 4 to $14 \mathrm{~mm}$, in a $25 \mathrm{~mm}$ internal diameter of OFR. Moreover, changes in $x_{o}$ affected $k L_{a}$ more than changes in the $f$, meaning that $x_{o}$ controls the length of eddy generated in the column.

Residence time distribution (RTD) affects heat transfer rates, interphase mass transfer rates and the conversion and selectivity of chemical and biochemical reactions. ${ }^{12}$ The RTD is an important concept used for analysis of reaction engineering with idealised models. As the name suggested, RTD indicates the spread of residence time experienced by different fluid elements while flowing through the reactor. ${ }^{10}$ The measurement of the outlet concentration of the reactor for a substance at known of their inlet concentration can be used to estimate the RTD of a given reactor. The RTD data and functions are essential as they will be used to make predictions of conversion and exit concentrations in a reactor. Hence, the aim of this work is to evaluate the effect of oscillation frequency and amplitude on the RTD for the MOBR.

The set-up of MOBR consists of a glass tube, one central baffle (Figure 1), three syringe pumps and one conductivity meter as in Figure 2. Their specification 


\section{Chemical Engineering Research Bulletin 19(2017) 111-117}

is tabulated in Table 2. Two reservoirs were provided for the continuous phase (water) and tracer (dilute KCL solution) respectively. Syringe pumps were used for; 1) inject the tracer, 2) provide a superficial flow and 3) oscillate the fluid inside the reactor.

Table 2: Design specification of MOBR.

\begin{tabular}{|c|c|}
\hline MOBR Specification & Dimensions \\
\hline Mixing mechanism & $\begin{array}{l}\text { Linear pulsing fluid from } \\
\text { the base }\end{array}$ \\
\hline $\begin{array}{l}\text { Column internal } \\
\text { diameter }(D)\end{array}$ & $5 \mathrm{~mm}$ \\
\hline Baffles spacing $(L)$ & $7.5 \mathrm{~mm}$ \\
\hline Overall height $(H)$ & $340 \mathrm{~mm}$ \\
\hline Overall volume & $8-10 \mathrm{ml}$ \\
\hline No. of baffles $(n)$ & 39 \\
\hline
\end{tabular}

At the outlet, the corresponding conductivity of the tracer was measured using an E61M014 conductivity probe of $4 \mathrm{~mm}$ in diameter and $103 \mathrm{~mm}$ in length (Mettler-Toledo, USA) connected to a CDM210 conductivity meter (Mettler-Toledo, USA). The data was recorded via computer. The tracers used in this study were dilute potassium chloride, $\mathrm{KCl}$ purchased from Sigma-Aldrich. Prior to the experiments, the conductivity probe was calibrated using a set of known $\mathrm{KCl}$ concentration at a fixed conductance range of $1413 \mu \mathrm{S} / \mathrm{cm}$ and inserted at the system outlet. The frequency was controlled by adjusting the speed of the piston movement, whereas the amplitude (centre-topeak) was adjusted by setting the amount of volume dispensed. These parameters were controlled and monitored by Sapphire Engineering Software (Eurodyne Ltd., UK) system via a RS232. An electric motor drives the oscillation and the speed of the motor provides oscillation frequencies between $5 \mathrm{~Hz}$ to $8 \mathrm{~Hz}$ and generates oscillation amplitudes of $1 \mathrm{~mm}$ to $5 \mathrm{~mm}$ (centre-to-peak). Before starting an experiment, the system was completely full and air-free. The pumps were adjusted to a required superficial velocity and oscillation condition (frequency and amplitude). A tracer amount of $0.5 \mathrm{ml}$ was injected at the inlet of the system located at the bottom of the tube at a highest flow rate in order to obtain a sharp pulse injection. RTD was quantified using statistical methods such as mean residence time, distribution curve, variance and skewness. The RTD profiles were analysed at a wide range of oscillation frequency, $f$ against the dynamic parameter of net flow Reynolds number $\left(R e_{n}\right)$, oscillatory Reynolds number $\left(R e_{o}\right)$ and Strouhal number (Str). The experiment was repeated three times with nearly identical results.

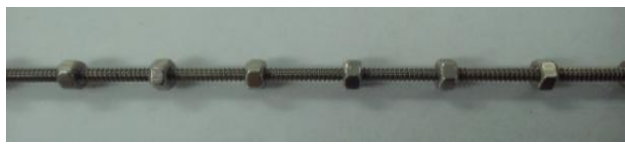

Figure 1: The central baffled design with stainless steel rods of $2 \mathrm{~mm}$ diameter and $340 \mathrm{~mm}$ lengths as supported rods.

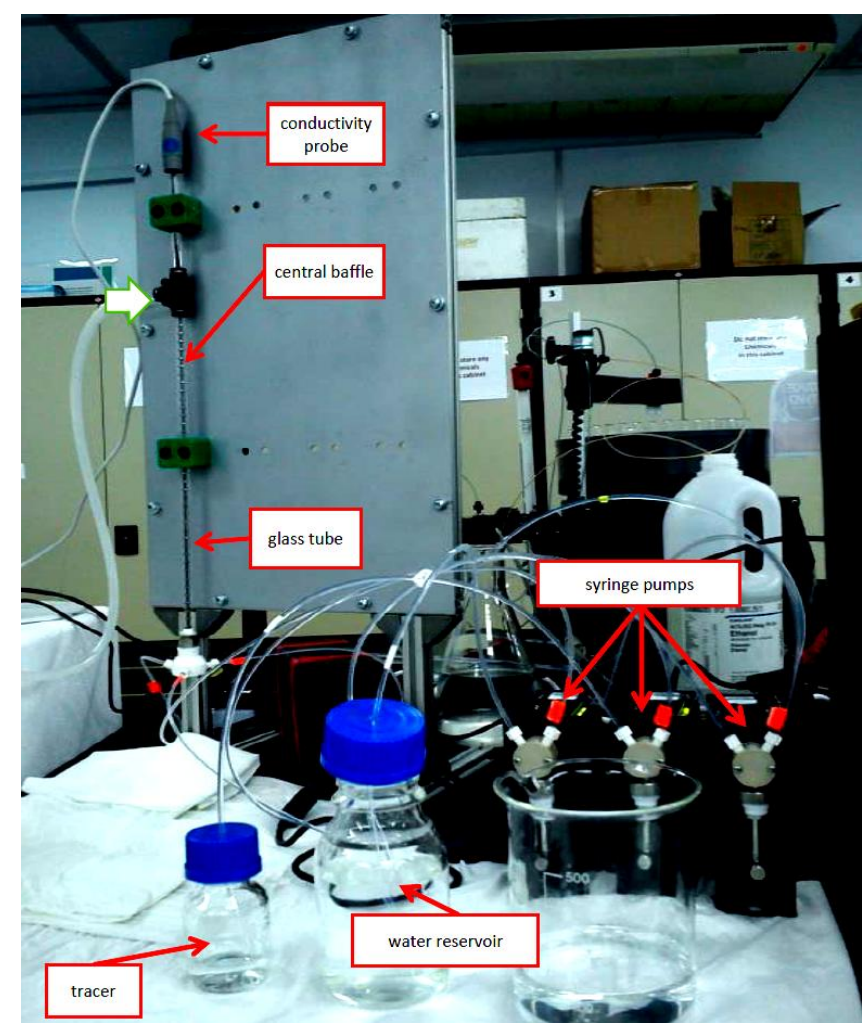

Figure 2: The experimental setup for MOBR.

\section{Results and Discussion}

\section{Residence time distribution}

Figure 3 shows the plot of tracer concentration at various points along the central baffles mesoreactor length versus time, with and without oscillation motion. In the presence of an oscillatory flow, a sharp and symmetrical RTD was observed at different measuring points responding to a near-pulse injection. This Gaussian RTD curve was obtained at the net Reynolds number of 12.6 superimposed with an oscillation frequency of $5 \mathrm{~Hz}$ and amplitude of $2 \mathrm{~mm}$. However, the distribution of the tracer slightly broadened and had a tailing to the right when the superimposed oscillatory flow was absent and only net flow was applied, i.e. there is no oscillation. This phenomenon was due to slow internal circulation within the system. This broadening is thought due to convection dispersion in laminar flow as similar 


\section{Chemical Engineering Research Bulletin 19(2017) 111-117}

phenomena was obtained when only net flow was applied in the helical baffled reactor. ${ }^{2}$ The mesoscale oscillatory baffled reactor design provided a welldefined and symmetrical RTD when an oscillatory flow was applied, which is the same behaviour as a conventional sharp-edge baffle reactor that has been developed earlier. ${ }^{13}$

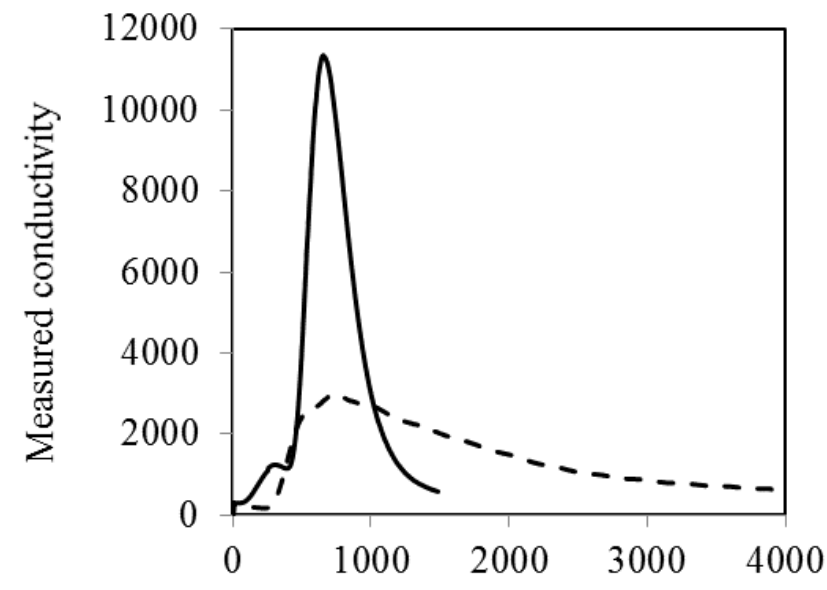

Time (s)

Figure 3: RTD profiles at oscillation condition: $R e_{n}=$ 12.6; $2 \mathrm{~mm} ; 5 \mathrm{~Hz}$ (dotted line: without oscillatory motion and solid line: with oscillatory motion).

Additionally, the RTD behaviour inside the MOBR in the absence of an oscillatory motion was compared at three different values of net flows which are $R e_{n}=4.2$, 8.4 and 12.6. It can be seen in Figure 4 that the RTD profile was long tailing at all those $R e_{n}$. Increasing the net flow up to $R e_{n}=12.6$ resulted in narrowed down the RTD curve and behaved similarly to that of a single stirred tank reactor. Without an oscillatory flow, the fluid mixing improved when $R e_{n}$ increased from 4.2 to 12.6 shown by a well-defined near Gaussian curve at $R e_{n}=12.6$. In addition, when applying an oscillatory flow at $5 \mathrm{~Hz}$ upon the net flow $R e_{n}$ of 12.6, the RTD curve became less skewed and approximately symmetric. There are two values of $R e_{o}$ for a central baffled tube subject to oscillatory flow that represent the thresholds between different flow patterns. Firstly, there is a minimum value at which symmetrical eddies are generated at $R e_{o}$ greater than 100 for OBRs. Secondly, there is a maximum value of $R e_{o}$ i.e. where the flow breaks its symmetry and becomes increasingly intense and chaotic. This occurs at $R e_{o}$ greater than 300 for OBRs. ${ }^{7}$

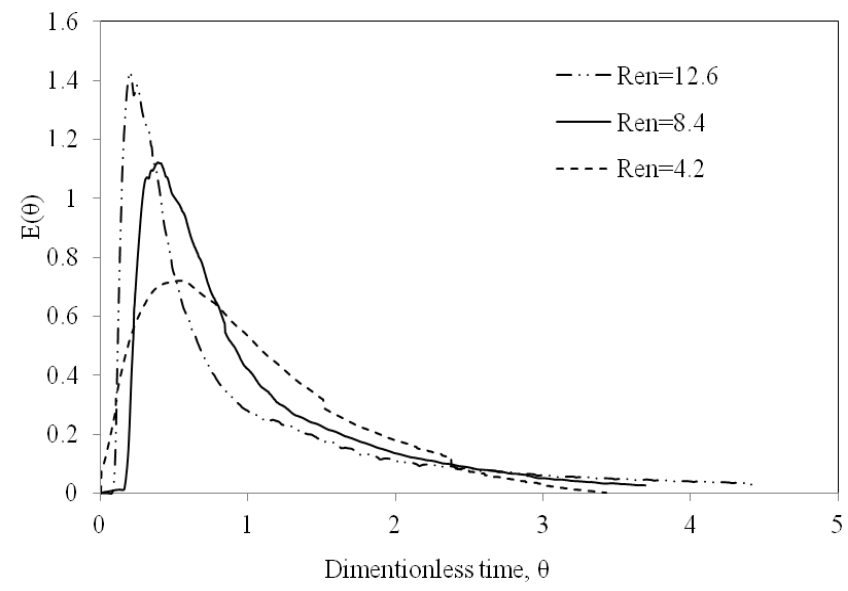

Figure 4: RTD curves at $R e_{n}=4.2,8.4$ and 12.6 without oscillatory flow.

\section{Effect of Oscillation Frequency}

RTD profiles obtained from the central baffle design are shown in Figure 5 at given net flow of $1.0 \mathrm{ml} / \mathrm{min}$, $R e_{n}$ of 4.2, amplitude of $2 \mathrm{~mm}$ and $S t r$ of 0.2. The variance of the RTD increased as the oscillation frequency increased from 5 to 8 and peaks at 6 as shown in Table 3. For example, the RTD in the central baffled reactor was close to that of a single stirred tank reactor at a frequency of $5 \mathrm{~Hz}$, corresponding to the narrowest RTD curve and smallest variance of 0.084 . A further increase in the frequency above $5 \mathrm{~Hz}$ caused the RTD to slightly broaden as shown in Figure 5, leading to a rise in variance as listed in Table 3.

Table 3: Effect of frequency on characteristics of RTD: variance (flow rate, $Q=1.0 \mathrm{ml} / \mathrm{min}$ and amplitude $x_{o}=2 \mathrm{~mm}$ ).

\begin{tabular}{|c|c|}
\hline Frequency, $\mathrm{Hz}$ & Variance, $\sigma(\theta)^{2}$ \\
\hline 5 & 0.084 \\
\hline 6 & 0.264 \\
\hline 7 & 0.136 \\
\hline 8 & 0.143 \\
\hline
\end{tabular}

\section{Effect of Oscillation Amplitude}

The effect of oscillation amplitude on the RTD was also studied at the range of amplitude, $x_{o}$ of $1 \mathrm{~mm}$ to 4 $\mathrm{mm}$. At a given frequency of $5 \mathrm{~Hz}$, the RTD profiles were close to Gaussian form for all tested amplitude values from $1 \mathrm{~mm}$ to $4 \mathrm{~mm}$ as illustrated in Figure 6 . It can be seen in Figure 6 that the distribution was narrower when amplitudes decreased to below $2 \mathrm{~mm}$. This can also be observed in Table 4, where the variances are 0.842 and 0.826 at amplitude $1 \mathrm{~mm}$ and 2 $\mathrm{mm}$, respectively. The RTD profiles approximated a 


\section{Chemical Engineering Research Bulletin 19(2017) 111-117}

completely mixed state at amplitudes higher than 2 $\mathrm{mm}$, indicating that axial mixing becomes dominant at these amplitudes. This is because oscillation amplitude directly relates to the length of eddies propagated inside each baffled cavity. ${ }^{13}$ Previous studies found that an increase in oscillation amplitude resulted in an increase in the size of eddies generated. ${ }^{14-15}$ It is thought that the vortices travel too far at higher amplitudes, such that they interact with adjacent baffles, thereby rendering the flow less like discrete tanks-in-series. ${ }^{13}$ This can be prevented in practise by observance of design rules based on maintaining the Strouhal number above certain values, for instances as listed in Table 4. Figure 7 shows the effect of amplitude on the variances over a wide range of oscillatory Reynolds numbers at a fixed net flow of $R e_{n}=12.6$. At low amplitudes, i.e. $x_{o}=1 \mathrm{~mm}$, the trend of variance versus $R e_{o}$ for the reactor was similar to that for the helical baffled design and central baffled design, ${ }^{7}$ where the variance exhibited its minimum at $R e_{o}=156$, and increased as $R e_{o}$ increased above that value. However, the variance decreased from 1.6 to 1.15 as $R e_{o}$ increased from 250 to 281 . At $R e_{o}$ above 300 , the variance increased rapidly to a value of around 1.28. It is thought that plug flow behaviour disappear and the reactor behaved similar to a single continuous stirred tank reactor.

Table 4: Effect of amplitude on characteristics of RTD: variance (flow rate, $\mathrm{Q}=3.0 \mathrm{ml} / \mathrm{min}$ and frequency $\mathrm{f}=5 \mathrm{~Hz}$ ).

\begin{tabular}{|c|c|c|}
\hline $\begin{array}{c}\text { Amplitude, } \\
x_{o}\end{array}$ & $\begin{array}{c}\text { Strouhal number, } \\
\text { Str }\end{array}$ & Variance, $\sigma(\theta)^{2}$ \\
\hline 1 & 0.40 & 0.842 \\
\hline 2 & 0.20 & 0.826 \\
\hline 3 & 0.13 & 1.712 \\
\hline 4 & 0.10 & 1.988 \\
\hline
\end{tabular}

At higher amplitudes, i.e. $x_{o}=2 \mathrm{~mm}, 3 \mathrm{~mm}$ and $4 \mathrm{~mm}$, the trend of variance versus $R e_{o}$ behaved very differently $^{7}$. At amplitude $2 \mathrm{~mm}$ and $4 \mathrm{~mm}$, the variance decreased with an increase of $R e_{o}$ up to 313 and 250 respectively. For example, at $x_{o}=2 \mathrm{~mm}$, the variance decreased to a value of 0.83 at $R e_{o}$ up to 313 . Then, the variance slightly increased to a value of approximately 1.25 with an increase of $R e_{o}$ up to 373 . After that, the variance slightly decreased to a value of 1.10 with an increase of $R e_{o}$ up to 435 . Finally, the variance increased rapidly at a value of 3.03 with an increase of $R e_{o}$ up to 497. At $x_{o}=3 \mathrm{~mm}$, the variance rose steadily to a value of 1.71 with an increase of $R e_{o}$ from 375 to 466 . Then, the variance decreased to a value approximately 0.46 with an increase of $R e_{o}$ up to
563. Finally, the variance increased rapidly from $R e_{0}$ 563 onward. At $x_{o}=4 \mathrm{~mm}(\mathrm{Str}=12.6)$, the variance remained at a value of approximately 1.00 with an increase of $R e_{o}$ up to 376 . Then the variance slightly rose from $R e_{o} 376$ to 500 before variance decreased rapidly down to 0.31 when $R e_{o}$ increased to 751 .

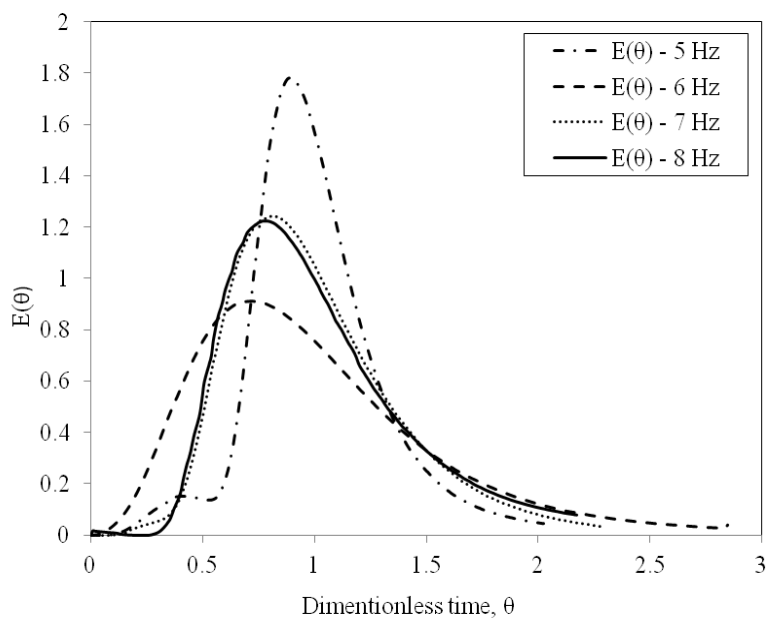

Figure 5: Effect of frequency on RTD profiles.

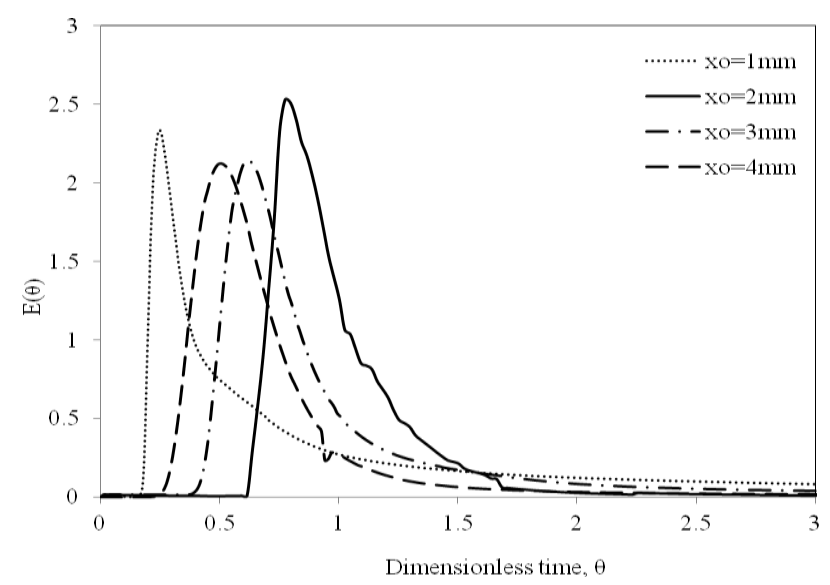

Figure 6: Effect on amplitude on RTD profiles at frequency $5 \mathrm{~Hz}$.

There is possibility of a swirling flow occurred at higher amplitudes, i.e. $x_{o}=2 \mathrm{~mm}, 3 \mathrm{~mm}$ and $4 \mathrm{~mm}$. The swirling flow can be only established when dispersed flow occurs at $R e_{o}>400 .{ }^{16}$ Whereas in oscillatory flow, it is believed that there is also a critical value of $R e_{o}$ where the swirling flow becomes active. It can be seen from Figure 7 that significant change in variance was obtained at $R e_{o}>400$, which might be the critical value of $R e_{o}$ in this case for amplitudes $x_{o}>2 \mathrm{~mm}$, which is thought due to the contribution of the swirling flow. 


\section{Chemical Engineering Research Bulletin 19(2017) 111-117}

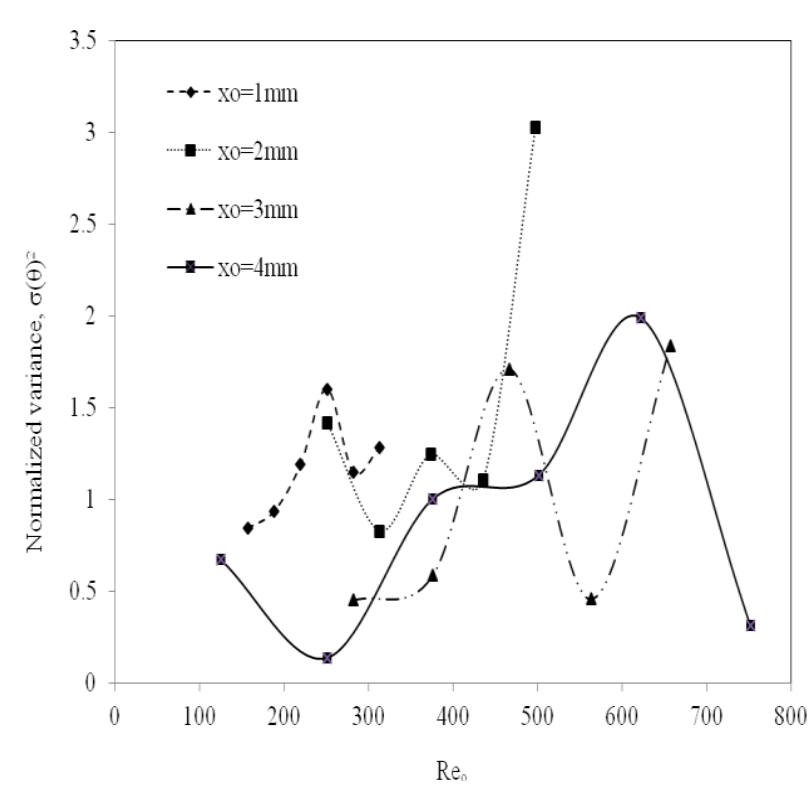

Figure 7: Variance versus oscillatory Reynolds number at $R e_{n}=12.6$; amplitude, $x_{o}$ at $1 \mathrm{~mm}-4 \mathrm{~mm}$.

\section{Conclusion}

The mesoscale oscillatory baffled reactor (MOBR) was successfully developed with central baffles system. Their mixing condition was evaluated in term of RTD performance and characterised at low net flow rates between 1.0 to $3.0 \mathrm{ml} / \mathrm{min}$ with highest $R e_{n}$ of 12.6 . This MOBR with central baffle reactor design provided a well-defined and symmetrical RTD when an oscillatory flow was applied. However, the RTD distribution was broadened and tailed to the right in the absent of oscillatory flow, which is due to the convection dispersion in laminar flow. The fluid mixing only improved near Gaussian curve when increasing the $R e_{n}$ to 12.6 resulted in narrowed RTD curve which behaved similarly to that of a single stirred tank reactor. The RTD curve became approximately symmetric when applying an oscillatory flow of $5 \mathrm{~Hz}$ at the net flow $R e_{n}$ of 12.6. It also influenced the normalized variance which decreased significantly to 0.826 at amplitude of $2 \mathrm{~mm}$ and $R e_{o}=$ 312.97. The $R e_{o}$ value which higher than 300 has resulted in the flow breaks its symmetry and becomes turbulent inside the MOBR. It is suggested that in this study, the fluid mixing induced at $R e_{o}$ higher than 300, amplitude, $x_{o}$ greater than $2 \mathrm{~mm}$, and Str smaller than 0.2 has made the plug flow behaviour disappear.

\section{Acknowledgement}

The authors wish to express their thanks to Ministry of Higher Education and Universiti Malaysia Pahang through the financial aid from grant RDU110333 and Universiti Malaysia Pahang's postgraduate research grants scheme (GRS120385).

\section{References}

1. N. Reis, A. P. Harvey, M. R. Mackley, M. R. Vicente, and J. A. Teixeira. "Fluid mechanics and design aspects of a novel oscillatory flow screening mesoreactor," Chemical Engineering Research and Design, vol. 83, no. 357-371, 2005.

2. A. N. Phan, and A. P. Harvey. "Effect of geometrical parameters on fluid mixing in novel mesoscale oscillatory helical baffled designs," Chemical Engineering Journal. vol. 169, no. 339347, 2011.

3. N. Reis, A. A. Vicente, J. A. Teixeira, and M.R. Mackley. "Residence times and mixing of a novel continuous oscillatory flow screening reactor," Chemical Engineering Science, vol. 59, no. 49674974, 2004.

4. X. Ni, M. R. Mackley, A. P. Harvey, P. Stonestreet, M.H.I. Baird, and N.V. Rama Raou. "Mixing through oscillations and pulsations-A guide to achieving process enhancements in the chemical and process industries," Trans IChemE, vol. 8, no. 373-383, 2003.

5. P. Stonestreet, and A. P. Harvey. "A mixing-based design methodology for continuous oscilltory flow reactors," Trans IChemE, vol. 80, no. 31-44, 2002.

6. D. Reay, C. Ramshaw, and A. Harvey. "Process Intensification. Engineering for efficiency, sustainability and flexibility," IChemE, UK, 2013.

7. A. N Phan, and A. P. Harvey. "Characterisation of mesoscale oscillatory helical baffled reactorExperimental approach," Chemical Engineering Journal, vol.180, no. 229-236, 2012.

8. M. S. R Abbott, A. P. Harvey, P. G. Valente, and M. K. Theodorou. "Biological processing in oscillatory baffles reactor operation, advantages and potential," Interface Focus, vol. 3, no. 20120036, 2013.

9. P. Gough, X. W. Ni, and K. C. Symes, "Experimental flow visualisation in a modified pulsed baffled reactor," Journal of Chemical Technology and Biotechnology, vol. 69, no. 321328, 1997.

10. N. Reis, C. N. Goncalves, M. Aguedo, N. Gomes, J. A. Teixeira, and A. A. Vicenta. "Application of a novel oscillatory flow micro-bioreactor to the production of $\gamma$-decalactone in a two immiscibble liquid phase medium," Biotechnology Letters, vol. 28 no. 485-490, 2006.

11. X. Ni, S. Gao, R. H. Cumming, and D. W. Pritchard. "A comparative study of mass transfer in yeast for a batch pulsed baffled bioreactor and a stirred tank fermenter," Chem. Eng. Sci., vol 50. no. 2127-2136, 1995. 


\section{Chemical Engineering Research Bulletin 19(2017) 111-117}

12. C. L. Briens, A. Margaritis, and G. Wild. "A new stochastic model and measurement errors in residence time distibutions of multiphase reacrors," Chemical Engineering Science. vol. 50, no. 279-287, 1995.

13. A. N. Phan, and A. P. Harvey. "Development and evaluation of novel designs of continuous mesoscale oscillatory baffled reactors," Chemical Engineering Journal. vol. 159, no. 212-219, 2010.

14. A. W. Dickens, M. R. Mackley, and Williams, H. R. "Experimental residence time distribution measurements for unsteady flow in baffled tubes,"
Chemical Engineering Science, vol. 44, no. 14711479, 1989.

15. E. P. L. Roberts, and M.R. Mackley. "The simulation of stretch rates for the quantative prediction and mapping of mixing within a channel flow," Chemical Engineering Science, vol. 50, no. 3727-3746, 1995.

16. A. Garcia, J. P. Solano, P. G. Vicente, and A. Viedma. "Flow pattern assessment in tubes with wire coil inserts in laminar and transition regimes," International Journal of Heat and Fluid Flow, vol. 28, no. 516-525, 2007.

\section{Available online at http://www.banglajol.info/index.php/CERB}

Publisher: Department of Chemical Engineering, Bangladesh University of Engineering and Technology (BUET). Review \&Publication: A submitted original manuscript is taken into review only if the uniqueness is found to be more than $85 \%$ in plag-scanning and selected for publication by the complete acceptance from at least two reviewers out of three. Home Page: http://www.banglajol.info/index.php/CERB . Indexed by Chemical Abstract Service (CAS), CEABA-VtB, Google Scholar, Scopus and DOAJ. 